\title{
Battles and breakthroughs: representations of dementia in the British press
}

\author{
Annika Bailey ${ }^{1 \star}$, Tom Dening ${ }^{2}$ and Kevin Harvey ${ }^{1}$ \\ ${ }^{1}$ School of English, University of Nottingham, Nottingham, UK and ${ }^{2}$ Division of Psychiatry and Applied \\ Psychology, School of Medicine, University of Nottingham, Nottingham, UK \\ ${ }^{*}$ Corresponding author. Email: annika.bailey@nottingham.ac.uk
}

(Accepted 18 July 2019; first published online 17 September 2019)

\begin{abstract}
Media coverage of dementia can influence public and professional attitudes towards the syndrome, shaping societal knowledge of dementia and impacting how people with dementia are cared for. This paper reports on a study of news articles about dementia published in the British press in the years 2012-2017. The analysis combines the tools of corpus linguistics, a methodology for quantitatively surveying a vast amount of electronic linguistic data, with the qualitative perspectives of Critical Discourse Analysis, which seeks to uncover dominant discourses and ideologies. The most salient discourse that emerged from this analysis was the portrayal of dementia in biomedical terms, with a particular focus on the pathological processes of dementia, and pharmaceutical treatments and research. Keywords relating to this discourse are interrogated in detail, illuminating the linguistic strategies through which the pathology of dementia and people with dementia are depicted. This study highlights the challenges that this type of reporting presents to people living with dementia and their families, and points to the relevance of a discursive approach to understanding societal perceptions of dementia.
\end{abstract}

Keywords: dementia; news media; biomedicine; corpus-assisted discourse analysis

\section{Introduction}

In the United Kingdom (UK), dementia is the leading cause of death for those aged 80 and over (Office for National Statistics, 2017), and the number of people diagnosed with dementia is increasing, predicted to reach two million people by 2051 (Alzheimer's Society, 2014). With no straightforward way to treat dementia, limited scientific understanding of the exact causes and processes, and currently no cure (Dening and Babu Sandilyan, 2015), dementia has come to invoke intense cultural anxieties about ageing, disability and death (Lock, 2013). A key site within which cultural perceptions of dementia are reproduced and legitimated is the news media (Basting, 2009). The news media is a vital source of information on health and wellbeing for the lay public (Lupton, 1999; Gwyn, 2001; Ramon, 2007). reproduction in any medium, provided the original work is properly cited. 
Informing on a range of topics such as what it is like to be ill, what causes illnesses and the development of treatments and cures, the news media has the power to shape discourses and ideologies surrounding health and illness (Seale, 2003).

The aim of the present study is to interrogate the popular discourses that surround dementia in the British news media, combining quantitative and qualitative methodological tools to consider a five-year period of reporting. Previous analysis of news reports of dementia shows that there is a bias towards the biomedical side of the syndrome, with the news media predominantly reporting on clinical research of drug treatments and cures, as well as the pathology of the condition and possible preventative strategies (Clarke, 2006; Kirkman, 2006; Kang et al., 2010). Headlines such as 'Alzheimer vaccine passes crucial test' (Kirkman, 2006) raise expectations and hopes for an imminent cure, which is at odds with the scientific reality, while framing dementia within this biomedical discourse obscures the relevance of the social and political impact of the syndrome (Clarke, 2006). Moreover, the discourse of biomedicine prioritises the voices of scientists and clinicians at the expense of those with the condition, such that people with dementia are significantly absent in stories about dementia (Van Gorp and Vercruysse, 2012; Siiner, 2019).

Another commonly identified theme in news reporting of dementia is a preventative discourse. Analysing five major Australian newspapers, Lawless and Augoustinos (2017) found articles which claimed to give 'advice' about dementia preventative behaviour, with readers positioned as responsible for their brain health. The implicit assumption is that people with dementia are at fault for developing the syndrome. Peel (2014) illuminates the presence of this discourse in the UK news media, too. Advice-giving, which was often contradictory, was found to make up a significant portion of Peel's one-year sample of news articles on dementia. The advice often appeared paradoxically alongside news coverage which incited panic about the catastrophic 'tsunami' of dementia. Peel labels this a 'panic-blame' framework and highlights its insidious nature, whereby people with dementia are constructed as being at fault for a 'global epidemic'.

Dementia as a syndrome is often characterised in the news media as a violent invader with the power to harm the individual physically (Clarke, 2006; Van Gorp and Vercruysse, 2012; Johnstone, 2013). This imagery is evident in descriptions of dementia as a 'killer' and other such depictions that centre on dementia's ability to inflict suffering and physical pain (Brookes et al., 2018). A consequence of this violence metaphor is the encouragement of military responses to 'combat' and 'fight' dementia (Van Gorp and Vercruysse, 2012). Many scholars have discredited military metaphors in relation to dementia, on the basis that the focus on 'fighting' assumes an outcome of either victory or death, and reduces the opportunities to consider palliative or other models of care (Lane et al., 2013).

News reports frame events, people and concepts in certain ways based on the news media's criteria for what is newsworthy (Bell, 1991; Fowler, 1991) and thus there exists the potential for inaccurate or misleading reporting about health and illness (Seale, 2003). There is a risk that reporting of health and illness in certain ways may generate false hopes and incite unwarranted fears (Shuchman and Wilkes, 1997). Medical reporting often relies on stories of villains and freaks, victimhood, professional heroes, lay heroes and the dangers of modern life (Seale, 
2003). A discourse of science fiction is also common, with allusions to plague and apocalypse (Gwyn, 2001). Moreover, with regards to news reporting of medicine and medical research, the news media has been criticised for being sensational (Shuchman and Wilkes, 1997), misleading (Moynihan et al., 2000), and lacking adequate discussion of the costs, benefits and harms of treatment and research (Schwitzer, 2008). Wilson et al. (2009) observed in medical news stories that treatments and interventions were typically portrayed as 'breakthroughs' or 'cures', which raised false hopes among readers. Another recurring feature is that medical news stories may only acknowledge two extremes of the story, rather than including caveats or information that better contextualises clinical research (Shuchman and Wilkes, 1997). However, Seale (2003) cautions that one must bear in mind that some degree of simplification is necessary in order to convey complex ideas to a lay audience and, furthermore, that the news media exists to provide entertainment, rather than accurate health information.

Interrogating the stories told about dementia in the news media can shed light on how dementia is popularly conceptualised and understood (Basting, 2009). In turn, it might be possible to challenge stigma and misconceptions to improve the wellbeing of people with dementia and their care-givers (Swinnen and Schweda, 2015). Building upon previous thematic analyses of news reports of dementia (Clarke, 2006; Kirkman, 2006; Kang et al., 2010; Peel, 2014; Lawless and Augoustinos, 2017), this study takes a linguistic approach to examine 3,000 news articles about dementia published in the British press between 2012 and 2017. The methods of corpus linguistics, a computational methodology for quantifying language patterns in electronic data, are combined with Critical Discourse Analysis (CDA), a qualitative approach that centres on highlighting powerful discourses and ideologies, to address the following research questions:

- What are the most dominant discourses drawn upon to depict dementia in the British news media?

- How do these discourses construct the syndrome, and those living with it?

- What are the implications for cultural understandings of dementia?

\section{Methods}

The methodological combination of corpus linguistics and CDA allowed for the quantitative identification of the most salient linguistic features in the data, followed by a qualitative consideration of how these features contributed to the dominant discourses surrounding dementia. Corpus linguistic tools allow the researcher to quantify a large amount of electronic data using a specialised computer program (Cheng, 2011). Corpus software can identify word frequencies, collocations (statistically significant recurrent associations between words across the corpus) and keywords (words which appear statistically significantly more frequently in one corpus compared with another), and can produce concordances (all instances of a particular word in its original context) (Baker, 2010). In the context of health communication research, corpus methodologies have been shown to generate deeper insights into language use than could be gleaned by qualitative analysis alone (Brown et al., 2006). Corpus-assisted approaches have been utilised to examine the most frequent 
words and phrases used in such areas as doctor-patient interactions (Skelton and Hobbs, 1999; Adolphs et al., 2004), as well as online health fora (Harvey, 2013; Hunt and Harvey, 2015) and health policy documents (Koteyko et al., 2008). The corpus tools employed in these studies have not been ends in themselves, but rather point the way for explanation of how certain linguistic features function in their context (Atkins and Harvey, 2010).

In this study, the methods of corpus linguistics identified salient linguistic features which featured prominently across the corpus. These features were then analysed in contextual detail from the perspectives of CDA. CDA seeks to understand and critique how discourses, especially hegemonic discourses, express and legitimise social inequality (Wodak, 2001), aiming to expose the ideologies underpinning discourses and 'make the implicit explicit in language use' (Flowerdew and Richardson, 2018: 1). Discourses are understood to be the 'set of meanings, metaphors, representations, images, stories, statements and so on that in some way together produce a particular version of events' (Burr, 2015: 74-75). Ideologies, defined as shared systems of beliefs among a social group that influence their interpretation of events and their social practices, are visible in and contribute to discourse (Van Dijk, 1998). A CDA approach thus combines a linguistic description of the text, a critical interpretation of the discourses embedded within that text and an explanation of how those discourses contribute to social reality (Fairclough, 2015). Texts from the mass media lend themselves particularly well to CDA research, since CDA's explicit intention is to uncover and critique hegemonic discourses, the likes of which are commonplace in the mass media (Hart, 2014).

The methodological combination of CDA with corpus linguistics lends representativeness and validity to the research, since it is feasible to consider a much larger data-set and analyse the most frequently occurring textual items, rather than 'cherry-pick' the linguistic features that prove a pre-conceived idea (HardtMautner, 1995; Widdowson, 1996; Toolan, 1997). In the context of the news media, this approach has been shown to be especially useful; single news articles may be insignificant in their effect on the reader, but powerful discourses emerge cumultatively, through recurrent representations and positionings (Fairclough, 2015). Moreover, the tools of corpus linguistics assist the researcher in identifying a starting point for analysis. For instance, work by Baker and colleagues (Baker et al., 2008; Gabrielatos and Baker, 2008) has explored the methodological implications of using corpus-based CDA to analyse representations of refugees and asylum seekers in a 140 million-word corpus of British newspaper articles. The quantitative measure of keywords and collocates allowed the researchers to hone in on statistically significant representations of refugees and asylum seekers, such as the frequent collocations that associate refugees and asylum seekers with illegal behaviour ('bogus asylum seekers', 'illegal immigrants', 'refugees trying to sneak into Britain'). From there, the authors were able to relate these linguistic features to the discourses prevalent across the corpus, thus generating an insightful picture of the portrayal of refugees in the British press.

In order to expand on earlier thematic work on news media representations of dementia, the present study compiled a corpus of news articles using the online news database Nexis UK. The database was searched for all articles published in 
British national newspapers between 1 March 2012 and 1 March 2017 that contained 'dementia' or 'alzheimer' in the headline or lead paragraph. These dates reflect a period of development and change within the UK in dementia research and care. In March 2012, Prime Minister David Cameron launched a strategy known as the 'Prime Minister's Challenge on Dementia' to make major improvements to dementia care and research within the next three years (Department of Health, 2012). This strategy was reinstated in 2015 to co-ordinate ongoing efforts up until 2020 (Department of Health, 2015). By collecting data from the announcement of this strategy, the corpus covers a period of political, scientific and social development during this time. A five-year period was selected to generate as broad a data-set as possible, within the limits of the data collection period (which took place in September 2017). The terms 'dementia' and 'Alzheimer's' are often used synonymously in the news media (Zeilig, 2015), so it was prudent to search for both terms when constructing the corpus. All told, the corpus consisted of 3,022 news items from all ten national newspapers (including Sunday editions).

The analysis began by calculating the 'keywords' in the corpus (those words which appear statistically significantly more frequently in the corpus than would be expected, based on their comparative frequency in a corpus of general language; Stubbs, 2010). In order to generate a list of keywords, and in line with many other health communication researchers (e.g. Harvey, 2013; Crawford et al., 2014; Atanasova et al., 2019), the corpus of news articles was compared with the British National Corpus, a collection of 90 million words of written British English from a variety of contexts, accepted among corpus linguistic researchers to be representative of British English. This quantitative analysis produced a list of keywords which could then be analysed in contextual detail, applying the qualitative perspectives of CDA to shed light on dominant discourses about dementia.

\section{Results and discussion}

Table 1 presents the keywords that occur significantly more frequently in the corpus of news articles than in general language. For the sake of space, only the top 30 keywords have been displayed. Table 1 provides the raw frequencies of each word in the corpus of news articles, as well as their 'keyness' scores which judge the statistical difference between a word's frequency in the news corpus compared with the British National Corpus (Rayson, 2013). A keyword list can highlight the dominant themes and topics contained within a corpus and thus forms a valuable starting point in the analysis of a corpus (Scott and Tribble, 2006).

Given that all the news articles in the corpus were collected on the basis of featuring 'dementia' or 'alzheimer' in the headline within a specified time-span, it is unsurprising that dementia, alzheimer's and disease appear as the most 'key', that is, they occur more frequently than would be expected in general language. Beyond these keywords, a theme which emerges prominently in the keyword analysis is that of biomedicine. This is apparent in Table 1 through the range of keywords relating to medical practice (care, diagnosed, diagnosis, symptoms), research (research, study), biology (brain, amyloid, cognitive), causation (risk), treatments (drug) and the various individuals involved in this biomedical paradigm (patients, 
Table 1. Top 30 keywords identified when comparing corpus of news articles with the British National Corpus

\begin{tabular}{|c|c|c|c|}
\hline & Keyword & Frequency & Keyness \\
\hline 1 & Dementia & 21,884 & $149,460.5$ \\
\hline 2 & Alzheimer's & 13,739 & $97,508.6$ \\
\hline 3 & Disease & 9,367 & $42,031.4$ \\
\hline 4 & Brain & 7,704 & $38,777.3$ \\
\hline 5 & It's & 3,749 & $26,593.2$ \\
\hline 6 & Care & 6,589 & $16,748.8$ \\
\hline 7 & Memory & 4,258 & $15,649.2$ \\
\hline 8 & People & 12,015 & $14,995.2$ \\
\hline 9 & Research & 6,159 & $13,884.6$ \\
\hline 10 & Don't & 1,869 & $13,256.2$ \\
\hline 11 & Risk & 4,327 & $12,707.2$ \\
\hline 12 & Patients & 4,347 & $10,280.9$ \\
\hline 13 & Diagnosed & 1,735 & $9,437.5$ \\
\hline 14 & Amyloid & 1,333 & $8,926.2$ \\
\hline 15 & Said & 12,773 & $8,603.6$ \\
\hline 16 & I'm & 1,179 & $8,362.0$ \\
\hline 17 & Cognitive & 1,732 & $8,334.0$ \\
\hline 18 & Study & 4,203 & $8,310.3$ \\
\hline 19 & Researchers & 2,014 & $8,267.5$ \\
\hline 20 & Diagnosis & 1,824 & $8,192.1$ \\
\hline 21 & Condition & 2,765 & $7,851.2$ \\
\hline 22 & Didn't & 1,102 & $7,815.8$ \\
\hline 23 & Scientists & 2,094 & $7,769.9$ \\
\hline 24 & Drug & 2,352 & $7,666.0$ \\
\hline 25 & Symptoms & 1,931 & $7,245.0$ \\
\hline 26 & Can't & 995 & $7,056.9$ \\
\hline 27 & $\mathrm{Dr}$ & 2,875 & $6,544.0$ \\
\hline 28 & Sufferers & 1,267 & $6,430.2$ \\
\hline 29 & Health & 3,785 & $6,403.4$ \\
\hline 30 & That's & 842 & $5,791.7$ \\
\hline
\end{tabular}

researchers, scientists, Dr). This finding supports earlier research into the portrayal of dementia in the news media which highlighted a heavy reliance on a discourse of biomedicine (Clarke, 2006; Kirkman, 2006; Kang et al., 2010; Van Gorp and Vercruysse, 2012). The statistical saliency of these keywords, indicating that they 
are overly represented in the corpus, points to a dominant discourse of biomedicine that is drawn upon to frame and discuss dementia.

In order to pursue how this discourse of biomedicine is articulated in the corpus, a selection of the most salient keywords were analysed in detail, utilising the corpus tools of collocation analysis-measuring statistically significant associations between words - and concordance analysis - viewing words and phrases in their original context. As the strongest keyword relating to biomedicine, the keyword brain provides a useful entry point into this discourse. In and of itself, the keyword does not reveal much beyond a potential preoccupation in the corpus with biology. Further insights can be gleaned by looking at the collocates of brain, which locate this keyword firmly in the sphere of dementia pathology; words that frequently co-occur with brain include 'cells', 'neurons', 'plaques', 'protein' and 'amyloid'. In scientific terms, amyloid is a type of protein that builds up between brain cells (or neurons) to form what are known as 'plaques' that block the synapses in the brain from functioning correctly (Alzheimer's Association, 2018). These neurobiological changes are the hallmark of Alzheimer's disease. Close examination of the context in which these collocates of brain occur indicates that these complex scientific processes are often explained and described using metaphor. The following concordance lines have been selected to show a range of metaphoric descriptions of the keyword brain in context (the keyword is italicised and collocates underlined):

(1) Pro-inflammatory cytokines cause the synapses, the connections between brain cells, to misfire. Eventually the whole organisation of the brain falls into disarray, like a failing computer, and neurons die. (Daily Mail)

(2) Studies on Alzheimer's patients have revealed the build-up of protein 'plaques' in the brain, which are thought to kill off brain cells. (The Guardian)

(3) In Alzheimer's disease, sticky beta-amyloid plaques build up between brain cells, like a blockage in a pipe. Solanezumab ... seeks out the early form of beta-amyloid before it becomes sticky and latches on. (Daily Telegraph)

(4) LMTX ... dissolves the tangles of protein that are a hallmark of the disease and spread through the brain like an infection, stopping them working from within. (Daily Mail)

Several related metaphors emerge here. In Extract 1, the dementia brain is likened to a failing machine: there is a circuit board ('wiring'), an engine ('misfire') and a 'failing computer'. The metaphor of 'body as a machine' is prevalent in the language of disease pathology and physiology, but critics posit that this metaphor is problematic since it attributes machine-like characteristics to living beings and suggests that patients are all identical and passive (Hodgkin, 1985). Moreover, in this context, the metaphor separates the individual from the social and political context; dementia pathology is imagined as a personal, isolated phenomenon that takes place within a very localised context. Another salient metaphor depicting the dementia brain conceptualises the brain as a battleground between dementia pathology and pharmaceutical drugs. The neurobiological markers of dementia are constructed as enemies of the brain's cells ('kill off, Extract 2). Because the metaphor only encompasses these two opposing entities, the battle is disconnected from 
human intervention. This de-personalises the descriptions of the disease process, since the individual with Alzheimer's disease is excluded as a social actor. A third metaphor evident in discussion of the pathology of dementia is that of the progression of dementia as a build-up of waste, and the treatment for dementia as waste disposal. We see this in Extract 3: 'like a blockage in a pipe', 'becomes sticky and latches on'. The suggestion is that the plaques that cause dementia are unpleasant, unsanitary waste materials that need to be flushed out in order for the brain to function correctly. This is related to the metaphor of infection visible in Extract 4, in which the proteins that cause Alzheimer's disease are likened to an 'infection' of the brain. Associating dementia with an infectious disease heightens cultural fears surrounding the syndrome (Johnstone, 2013; Zeilig, 2013). Within these metaphors of dementia as waste build-up and dementia as infection, the pathology of dementia is imagined as a physical, quantifiable entity within the brain requiring pharmaceutical treatments to 'flush out' or clean the system.

Metaphors are a useful linguistic strategy when explaining abstract or complex ideas, and are readily apparent in discussions of such topics as illness and death (Demmen et al., 2015). Dementia is often described in metaphorical terms in popular culture, with pervasive metaphors including a zombie apocalypse (Behuniak, 2011), a military battle (George and Whitehouse, 2014) and an epidemic (Zeilig, 2013; Johnstone, 2016). The corpus of news articles draws heavily on the metaphors represented above, using the language of machinery, warfare, waste disposal and infection to communicate to a lay audience the neurological processes that result in the symptoms of dementia. Within the discourse of biomedicine, these metaphors reduce dementia to a set of pathological processes, devoid of the personal or social implications of the condition. Moreover, people with dementia are backgrounded and given no agency, be it through rendering the brain an inanimate object (such as a circuit board or a drainage system), ascribing machine-like qualities to the cells and processes, or personifying dementia pathology as a killer.

People with dementia are further obscured in the discussions of treatments for dementia. Although there are a variety of pharmaceutical and non-pharmaceutical treatments available to manage the symptoms of dementia (Dening and Babu Sandilyan, 2015), the corpus of news articles predominantly focuses on drug treatments. Of all the keywords in the corpus relating to the treatment of dementia, the word drug appears statistically significantly the most frequently. Collocation analysis reveals that $d r u g$ strongly collocates with words relating to temporal relevance - 'new', 'discovery', 'development', 'breakthrough' - as well as clinical research - 'trials', 'tested', 'licensed', 'experimental' - and speed - 'slow', 'stop', 'halt'. This latter category sheds more light on how the disease process is conceptualised alongside the positioning of treatment options, as the following extracts show:

(5) Alzheimer's drug that may slow condition hailed as 'glimmer of hope'. (Independent)

(6) Scientists have made a vital breakthrough in the fight against Alzheimer's disease by developing a drug that could stop it in its tracks. (Express Online) 
(7) Mental exercises have also shown promise in delaying memory loss, but the main aim of dementia research is a drug to halt the disease by preventing damage to neural tissue. (The Times)

(8) Drug to reverse Alzheimer's could be just years away, scientists said last night. (Express Online)

Dementia is imagined as some form of moving entity while drug treatments are conceptualised as a barrier to the encroaching condition that may 'slow' or 'reverse' the advance or terminate it altogether ('stop', 'halt'). Constructing a disease as an invader is a common trope in the mass media, with the disease positioned as external to the individual and the body as a battleground upon which doctors fight (Gwyn, 2001). This type of metaphor normalises and promotes a military response (Johnstone, 2016). Extracts 5-8 depict a battle between dementia and the pharmaceutical treatment, while the scientists are backgrounded (Van Leeuwen, 1995), if mentioned at all. People with dementia have no agency; they are depicted as merely the space upon which dementia advances and pharmaceutical drugs resist. Meanwhile, the discourse of biomedicine places great emphasis on the power of pharmaceutical treatments; the keyword drug is recurrently described using the adjectives 'breakthrough' and 'wonder', particularly in headlines and lead paragraphs:

(9) Drug could be breakthrough for Alzheimer's; Dementia experts hail 'real hope' for disease victims. (Daily Telegraph, headline)

(10) Breakthrough drug has been shown to halt or even reverse the devastating progression of Alzheimer's disease. (Daily Mail, lead paragraph)

(11) Millions could be offered wonder drug to prevent Alzheimer's before symptoms appear. (Express Online, headline)

(12) British scientists have hailed liraglutide as a wonder drug that could prove the first effective weapon in the fight against the condition. (Express Online, lead paragraph)

To describe a drug as a 'breakthrough' or 'wonder' is to highlight that the drug has surpassed all expectations and extended previous scientific boundaries and limitations. The hyperbolic language here frames the drugs as the heroes of the story: the bringer of 'real hope' and the saviour of 'disease victims' (Extract 9); stopping the 'devastating' (Extract 10) disease; making an impact on 'millions' (Extract 11); involved in the 'fight' (Extract 12). Pharmaceutical drugs are positioned as saviours in the perceived crusade against dementia, with many military references to bolster the heroism of the drugs. By constructing these drugs as miraculous and unprecedented, and contrasting this with language that emphasises the horror of dementia, these headlines assert a sense of urgent need for the pharmaceutical interventions. Given that these adjectives typically modify drug in headlines or lead paragraphs, it must be acknowledged there is an element of reeling the reader into the story with a hyperbolic opening (Bell, 1991). Shuchman and Wilkes (1997) posit that this type of sensationalist reporting of clinical research ultimately benefits researchers, through raising awareness of the need for research and potentially generating research funding. Thus, the biomedical discourse supports and celebrates clinical 
research, and encourages readers to do the same. However, the representations of a 'breakthrough/wonder drug' imply that the treatment is singular and curative, which is at odds with current scientific understandings of dementia and therefore highly misleading.

It has thus far been evident that people with dementia are afforded very little agency within this biomedical discourse, and this is reinforced through the labels used to denote people living with dementia. The labelling of social actors in the news media has a significant ideological function, sculpting how readers can understand the individuals in question and generalise about them (Bell, 1991; Matheson, 2005). The labels patients and sufferers, appearing as 'keywords' because they are overly represented in the corpus compared to general language use, are the most common referents for people with dementia, and predominantly appear in discussions of clinical research, medical diagnoses and long-term care of people with dementia. Both labels overwhelmingly position people with dementia as lacking agency within this biomedical paradigm, as the following examples show:

(13) Elderly dementia patients were kept like 'captured animals' on a mental health ward with relatives comparing their treatment to a 'zoo,' a damning report has revealed. (Daily Mirror)

(14) Scientists hope to start trials in dementia patients after rat study suggests drug reduces brain inflammation and encourages neuron growth. (The Guardian)

(15) Dementia sufferers have been left to starve or live on biscuits, with others left in soiled sheets and dirty clothes, according to a damning report warning of failures to care for the vulnerable. (Daily Telegraph)

(16) The first trial of the drug on Alzheimer's sufferers was deemed a failure, but a follow-up study found that a specific group of newly diagnosed patients saw a modest improvement - a 30\% slowdown in the disease. (The Times)

Although taken from a range of contexts, these short extracts give a flavour of the positioning of patients and sufferers within a predominantly medical or clinical environment. Typically, patients and sufferers are grammatically positioned using the passive voice (Thompson, 2014), as Extracts 13 and 15 illustrate. In this way, patients and sufferers are always being acted upon rather than being the 'doer' of the action. The other social actors (e.g. the people keeping 'dementia patients' on the hospital ward; Extract 13) are not mentioned at all; their role in the action is suppressed (Van Leeuwen, 1995). The absence of other named social actors gives the impression that the patients and sufferers are at the mercy of anonymous medical authorities, continuously being acted upon rather than acting for themselves with regards to their care and treatment. Moreover, patients and sufferers are recurrently depicted merely as the site upon which clinical research takes place. Extracts 14 and 16 aptly demonstrate this phenomenon: 'trials in dementia patients' (Extract 14); 'trial of the drug on Alzheimer's sufferers' (Extract 16). The use of prepositions signals that patients and sufferers are no more than receivers of the action, and they have no contribution to or influence over what happens to them in their treatment. This grammatical passivity suggests that patients and sufferers are simply voiceless, anonymous bodies for medical science to experiment upon. Such a positioning of 
people with dementia as passive in their medical encounters and treatment processes is in accordance with traditional cultural understandings of 'patients' and people who are ill (Fisher, 1984; Frank, 2013).

Lexical choices seek to de-humanise patients and sufferers too, implying that people with dementia are feeble and dependent, and possibly even sub-human. They are likened explicitly to 'captured animals' in a 'zoo' (Extract 13), which contributes to the understanding that people with dementia are completely helpless and reliant on others for care. This shares similarities with Clarke's (2006) observation that the news media tends to treat people with dementia as if their human rights are lessened because the person 'isn't really there'. Additionally, Extracts 13 and 15 paint a highly pejorative picture of care standards, with implications of cruelty and de-humanisation. These extracts represent an emerging branch of the discourse of biomedicine, specifically a discourse of abuse within clinical settings, which sees patients and sufferers as victims of widespread abuse and neglect. By contrasting the dependency of patients and sufferers with descriptions of abuse, these news articles emphasise that dementia leaves a person unable to protect themselves. The adjectives used to modify patients and sufferers are also telling: 'elderly', 'vulnerable', 'older' and 'frail' collocate strongly with both patients and sufferers, reinforcing the assumption that people with dementia are inherently weak. The overall impression within the discourse of biomedicine is that patients and sufferers of dementia are defenceless and rely on healthy others in order to function in day-to-day life. This portrayal of overwhelming vulnerability and passivity reduces people with dementia to their pathological deficits and ignores the possibility that people with dementia may continue to live well despite the condition.

\section{Conclusions}

In a corpus of five years of news reporting of dementia in the British national press, dementia was framed predominantly through a discourse of biomedicine. The prevalence of this discourse was evidenced in the number of keywords relating to disease pathology, medical interventions and clinical research, which the quantitative corpus analysis showed to be significantly more salient in the corpus than in general British English. A number of recurrent linguistic features associated with these keywords were analysed using a qualitative CDA approach to consider critically how the discourse of biomedicine was realised in the corpus, and the implications of this discourse on representations of the syndrome and those living with it.

Earlier research has noted the prevalence of a variety of metaphors used to depict dementia (Zeilig, 2013; Johnstone, 2016). Such metaphors tend to obscure the agency of the person with the syndrome and perpetuate fear and anxiety, such as in the metaphor of dementia as a zombie apocalypse which insinuates a global epidemic and promotes the belief that death is preferable (Behuniak, 2011). The present paper extends this body of work to pinpoint some of the most salient metaphorical representations of the pathological processes of dementia, located firmly within a biomedical discourse. These metaphors rendered the individual merely a passive vessel within which the syndrome progresses, excluding the person from the narrative. This supports previous assertions that the voices of people with dementia tend to be notably absent from news reports of the syndrome 
(Van Gorp and Vercruysse, 2012; Siiner, 2019). Meanwhile, pharmaceutical interventions took on heroic significance, framed as the only possible solution to prevent dementia. Moreover, the labelling of people with dementia as 'patients' and 'sufferers' conferred vulnerabilty and passivity, positioning people with dementia as a homogenous and anonymous group of social actors in the broader clinical environment, within which all authority lies with scientists, institutions and pharmaceutical treatments. This obscures the relevance of the social context within which the person with dementia lives (Basting, 2009).

The news media, as with all forms of discourse, represents the world through the lens of various ideological positions (Fowler, 1991). News stories are sculpted to present a particular attitude or belief, to obscure some social actors while emphasising others, to attribute or elide responsibility and agency, and so on (Van Dijk, 1988; Bell, 1991; Matheson, 2005). The pervasiveness of the biomedical discourse in news reporting of dementia suggests that the news media draws on several overarching ideologies to represent dementia: a medical ideology valorises science and research above other sources of knowledge, and an ageist ideology reduces elderly and ill people to their deficits. Notably, the reliance on the biomedical discourse conceals alternative discourses and ideologies, such as a discourse of political and social action which would reinforce dementia as a global issue requiring collective responses, rather than an individualised, isolated phenomenon, as the focus on pathological processes seems to suggest. Clarke (2006: 274) writes that the reliance on the biomedical discourse 'serves to reinforce the power of medicine and pharmaceuticals as the appropriate and benign instrument of social control'. Pharmaceutical treatments are overwhelmingly held in high regard, with the discourse of biomedicine excluding reference to the many types of nonpharmaceutical treatments such as cognitive stimulation therapy, reminiscence therapy and arts-based therapies (James and Fossey, 2013). The biomedical discourse foregrounds the need for a pharmaceutical cure, with little consideration of the importance of care and the social environment for a person living with the condition (Kitwood, 1997). Moreover, there is little evidence in the biomedical discourse that people with the condition may live full, active lives, despite the fact that it is very possible to continue to live well after a diagnosis of dementia with the right support (Swaffer, 2014). A discourse of living well with dementia, which would foreground the abilities rather than deficits of individuals with dementia, is conspicuously absent in the prevalent biomedical discourse, lending the impression that dementia equates to an automatic loss of agency and selfhood.

A key limitation of this study is that the methods of corpus linguistics decontextualise the data. That is to say that images, font sizes, layouts and other such multimodal aspects of the data are left out of the corpus, and thus the analysis. Although this analysis chose to focus only on the linguistic features of the texts, extending the analysis to include multimodal aspects, as demonstrated by Kessler and Schwender (2012) and Brookes et al. (2018), could illuminate how prominent discourses are realised through non-linguistic means. Moreover, corpus techniques illuminate multiple possible avenues for investigation, but inevitably due to time and space restrictions, only certain linguistic features can be analysed in close detail. Additionally, the individual researcher must decide which words to analyse in closer detail, and how to interpret them in context. This analysis centred on the 
discourse of biomedicine, which the keyword procedure showed to be the most prominent, and it is hoped that future research on this corpus, utilising the methodological combination of corpus linguistics and CDA, will consider other less prominent discourses, thus generating deeper insights into the linguistic depiction of dementia in the British press.

Financial support. This work was supported by the Arts and Humanities Research Council (grant number AH/L50385X/1). These financial sponsors had no involvement in the design or execution of the study.

Conflict of interest. The authors declare no conflicts of interest.

\section{References}

Adolphs S, Brown B, Carter R, Crawford P and Sahota O (2004) Applying corpus linguistics in a health care context. Journal of Applied Linguistics 1, 9-28.

Alzheimer's Association (2018) Alzheimer Basics: Plaques and Tangles. Available at https://www.alz.org/ norcal/in_my_community_20545.asp.

Alzheimer's Society (2014) Dementia UK Update. Available at https://www.alzheimers.org.uk/sites/default/ files/migrate/downloads/dementia_uk_update.pdf.

Atanasova D, Koteyko N, Brown B and Crawford P (2019) Representations of mental health and arts participation in the national and local British press, 2007-2015. Health 23, 3-20.

Atkins S and Harvey K (2010) How to use corpus linguistics in the study of health communication. In O'Keeffe A and McCarthy M (eds), The Routledge Handbook of Corpus Linguistics. London: Routledge, pp. 605-619.

Baker P (2010) Sociolinguistics and Corpus Linguistics. Edinburgh: Edinburgh University Press.

Baker P, Gabrielatos C, Khosravinik M, Krzyzanowski M, McEnery T and Wodak R (2008) A useful methodological synergy? Combining critical discourse analysis and corpus linguistics to examine discourses of refugees and asylum seekers in the UK press. Discourse \& Society 19, 273-306.

Basting A (2009) Forget Memory: Creating Better Lives for People with Dementia. Baltimore, MD: Johns Hopkins University Press.

Behuniak SM (2011) The living dead? The construction of people with Alzheimer's disease as zombies. Ageing \& Society 31, 70-92.

Bell A (1991) The Language of News Media. Oxford: Blackwell.

Brookes G, Harvey K, Chadborn N and Dening T (2018) 'Our biggest killer': multimodal discourse representations of dementia in the British press. Social Semiotics 28, 371-395.

Brown B, Crawford P and Carter R (2006) Evidence Based Health Communication. Buckingham, UK: Open University Press.

Burr V (2015) Social Constructionism. Hove, UK: Routledge.

Cheng W (2011) Exploring Corpus Linguistics: Language in Action. Abingdon, UK: Routledge.

Clarke JN (2006) The case of the missing person: Alzheimer's disease in mass print magazines 1991-2001. Health Communication 19, 269-276.

Crawford P, Brown B and Harvey K (2014) Corpus linguistics and evidence-based health communication. In Hamilton HE and Chou WS (eds), The Routledge Handbook of Language and Health Communication. Abingdon, UK: Routledge, pp. 75-90.

Demmen J, Semino E, Demjen Z, Koller V, Hardie A, Rayson P and Payne S (2015) A computer-assisted study of the use of Violence metaphors for cancer and end of life by patients, family carers and health professionals. International Journal of Corpus Linguistics 20, 205-231.

Dening T and Babu Sandilyan M (2015) Medical treatment and management of patients with dementia. Nursing Standard 29, 43-49.

Department of Health (2012) Prime Minister's Challenge on Dementia. London: Department of Health.

Department of Health (2015) Prime Minister's Challenge on Dementia 2020. London: Department of Health.

Fairclough N (2015) Language and Power. Abingdon, UK: Routledge.

Fisher S (1984) Doctor-patient communication: a social and micro-political performance. Sociology of Health and Illness 6, 1-29. 
Flowerdew J and Richardson JE (2018) Introduction. In Flowerdew J and Richardson JE (eds), The Routledge Handbook of Critical Discourse Studies. London: Routledge, pp. 1-11.

Fowler R (1991) Language in the News: Discourse and Ideology in the Press. London: Routledge.

Frank AW (2013) The Wounded Storyteller. Chicago, IL: University of Chicago Press.

Gabrielatos C and Baker P (2008) Fleeing, sneaking, flooding: a corpus analysis of discursive constructions of refugees and asylum seekers in the UK press, 1996-2005. Journal of English Linguistics 36, 5-38.

George DR and Whitehouse PJ (2014) The War (on Terror) on Alzheimer's. Dementia 13, 120-130.

Gwyn R (2001) Communicating Health and Illness. London: Sage.

Hardt-Mautner G (1995) 'Only Connect'. Critical discourse analysis and corpus linguistics. Lancaster University, Lancaster, UK, UCREL Technical Paper 6.

Hart C (2014) Discourse, Grammar and Ideology: Functional and Cognitive Perspectives. London: Bloomsbury.

Harvey K (2013) Investigating Adolescent Health Communication. London: Bloomsbury.

Hodgkin P (1985) Medicine is war: and other medical metaphors. British Medical Journal 291, 21-28.

Hunt D and Harvey K (2015) Health communication and corpus linguistics: using corpus tools to analyse eating disorder discourse online. In Baker P and McEnery T (eds), Corpora and Discourse Studies. London: Palgrave Macmillan, pp. 134-154.

James IA and Fossey J (2013) Nonpharmacological interventions in care homes. In Dening $\mathrm{T}$ and Thomas A (eds), Oxford Textbook of Old Age Psychiatry. Oxford: Oxford University Press, pp. 269-282.

Johnstone MJ (2013) Metaphors, stigma and the 'Alzheimerization' of the euthanasia debate. Dementia 12, 377-393.

Johnstone MJ (2016) Alzheimer's Disease, Media Representations and the Politics of Euthanasia: Constructing Risk and Selling Death in an Ageing Society. Abingdon, UK: Routledge.

Kang S, Gearhart S and Bae H (2010) Coverage of Alzheimer's disease from 1984 to 2008 in television news and information talk shows in the United States: an analysis of news framing. American Journal of Alzheimer's Disease \& Other Dementias 25, 687-697.

Kessler EM and Schwender C (2012) Giving dementia a face? The portrayal of older people with dementia in German weekly news magazines between the years 2000 and 2009. Journals of Gerontology: Psychological Sciences and Social Sciences 67B, 261-270.

Kirkman AM (2006) Dementia in the news: the media coverage of Alzheimer's disease. Australasian Journal on Ageing 25, 74-79.

Kitwood T (1997) Dementia Reconsidered: The Person Comes First. Buckingham, UK: Open University Press.

Koteyko N, Nerlich B, Crawford P and Wright N (2008) 'Not rocket science' or 'no silver bullet'? Media and government discourses about MRSA and cleanliness. Applied Linguistics 29, 223-243.

Lane HP, McLachlan S and Philip J (2013) The war against dementia: are we battle weary yet? Age and Ageing 42, 281-283.

Lawless M and Augoustinos M (2017) Brain health advice in the news: managing notions of individual responsibility in media discourse on cognitive decline and dementia. Qualitative Research in Psychology 14, 62-80.

Lock M (2013) The Alzheimer's Conundrum. Princeton, NJ: Princeton University Press.

Lupton D (1999) Editorial: Health, illness and medicine in the media. Health 3, 259-262.

Matheson D (2005) Media Discourses. Maidenhead, UK: Open University Press.

Moynihan R, Bero L, Ross-Degnan D, Henry D, Lee K, Watkins J, Mah C and Soumerai S (2000) Coverage by the news media of the benefits and risks of medications. New England Journal of Medicine 342, 1645-1650.

Office for National Statistics (2017) Deaths Registered in England and Wales (Series DR): 2016. Available at https://www.ons.gov.uk/releases/deathsregisteredinenglandandwalesseriesdr2016.

Peel E (2014) 'The living death of Alzheimer's' versus 'Take a walk to keep dementia at bay': representations of dementia in print media and carer discourse. Sociology of Health \& Illness 36, 885-901.

Ramon S (2007) Risk communication and the media. In Hillier D (ed.), Communicating Health Risks to the Public: A Global Perspective. London: Routledge, pp. 83-93.

Rayson P (2013) Corpus analysis of key words. In Chapelle CA (ed.), The Encyclopedia of Applied Linguistics. Hoboken, NJ: Blackwell Publishing, pp. 1-7. 
Schwitzer G (2008) How do US journalists cover treatments, tests, products, and procedures? An evaluation of 500 stories. PLOS Medicine 5, 700-704.

Scott M and Tribble C (2006) Textual Patterns: Key Words and Corpus Analysis in Language Education. Amsterdam: John Benjamins Publishing Company.

Seale C (2003) Health and media: an overview. Sociology of Health \& Illness 25, 513-531.

Shuchman M and Wilkes M (1997) Medical scientists and health news reporting: a case of miscommunication. Annals of Internal Medicine 126, 976-982.

Siiner M (2019) Let me grow old and senile in peace: Norwegian newspaper accounts of voice and agency with dementia. Ageing \& Society 39, 977-997.

Skelton JR and Hobbs FD (1999) Descriptive study of cooperative language in primary care consultations by male and female doctors. British Medical Journal 18, 576-579.

Stubbs M (2010) Three concepts of keywords. In Bondi M and Scott M (eds), Keyness in Texts. Amsterdam: John Benjamins Publishing Company, pp. 19-42.

Swaffer K (2014) Dementia and prescribed disengagement. Dementia 14, 3-6.

Swinnen A and Schweda M (2015) Popularizing dementia: public expressions and representations of forgetfulness. In Swinnen A and Schweda M (eds), Popularizing Dementia: Public Expressions and Representations of Forgetfulness. Bielefeld, Germany: Transcript Verlag, pp. 9-22.

Thompson G (2014) Introducing Functional Grammar. Abingdon, UK: Routledge.

Toolan M (1997) What is critical discourse analysis and why are people saying such terrible things about it? Language and Literature 6, 83-103.

Van Dijk TA (1988) News as Discourse. Hillsdale, NJ: Lawrence Erlbaum Associates.

Van Dijk TA (1998) Discourse and ideology. Discourse \& Society 9, 307-308.

Van Gorp B and Vercruysse T (2012) Frames and counter-frames giving meaning to dementia: a framing analysis of media content. Social Science \& Medicine 74, 1274-1281.

Van Leeuwen T (1995) The representation of social actors. In Caldas-Coulthard CR and Coulthard M (eds), Texts and Practices: Readings in Critical Discourse Analysis. London: Routledge, pp. 32-70.

Widdowson H (1996) Reply to Fairclough. Discourse and interpretation. Conjectures and reflections. Language and Literature 5, 57-96.

Wilson A, Bonevski B, Jones A and Henry D (2009) Media reporting of health interventions: signs of improvement, but major problems persist. PLOS ONE 4, 1-5.

Wodak R (2001) What CDA is about: a summary of its history, important concepts, and its developments. In Wodak R and Meyer M (eds), Methods of Critical Discourse Analysis. London: Sage, pp. 1-13.

Zeilig H (2013) Dementia as a cultural metaphor. The Gerontologist 54, 258-267.

Zeilig H (2015) What do we mean when we talk about dementia? Exploring cultural representations of 'dementia'. Working with Older People 19, 12-20.

Cite this article: Bailey A, Dening T, Harvey K (2021). Battles and breakthroughs: representations of dementia in the British press. Ageing \& Society 41, 362-376. https://doi.org/10.1017/S0144686X19001120 